\title{
Development and validation of a friction model for simulation of friction clutch dynamics in a multi-body system
}

\author{
T. Petrun ${ }^{1}$, M. Kegl ${ }^{2} \&$ J. Flašker ${ }^{2}$ \\ ${ }^{1}$ AVL-AST d.o.o., Slovenija \\ ${ }^{2}$ University of Maribor, Faculty of Mechanical Engineering, Slovenija
}

\begin{abstract}
This paper deals with the development and validation of a mathematical friction model for numerical friction clutch simulation within a dynamic multi-body system of complete vehicle powertrains to be used by the commercial numerical code AVL EXCITE. The corresponding requirements and demands of the automotive industry and the given software environment are presented along with the advantages of the new friction model. The focus is to find a model capable rendering important friction dynamics and true stick. Detailed tribological analysis of the developed friction model is done and results for the so called STICK/SLIP test are given, to show the capabilities and properties of the friction model. Validation of the developed friction model on a special test bed is presented. A comparison of experimental validation measurement results and numerical simulation results shows a remarkably good agreement.
\end{abstract}

Keywords: friction clutch, elasto-plastic friction model, true stick, multi-body system dynamics, experimental verification.

\section{Introduction}

The main focus of this research work is the development and validation of an advanced reliable friction model for numerical simulations of the friction clutch in a multi-body system (MBS). To improve and extend the functionality of the MBS software code AVL EXCITE with a fully functional friction clutch model, we need to find the most appropriate friction model and adapt it to the demands and requirements of the application and the software environment. 
Based on the literature many friction models of different complexity were proposed [1-15]. The complexity of those models is determined by friction contact description. The simplest and most common friction model is the Coulomb friction model [1], where friction force $F_{C f}$ is defined as a product of the normal force $F_{n}$ and the friction coefficient $\mu$, eqn. (1).

$$
F_{C f}=F_{n} \mu
$$

This model considers the friction coefficient to be constant over the whole range of relative sliding velocities, temperature, normal force, direction, etc. On the other hand, the most complex friction model, the Leuven friction model [14], considers the friction coefficient as a function of sliding velocity, normal force, time, sliding direction - hysteresis effect, etc. Since friction is a high nonlinear dynamic effect and was studied by many authors [16-26], the capabilities of each friction model to render friction dynamics depend on how each model considers the friction coefficient.

\section{Objectives and requirements}

The target software for implementation deals with multi-body systems with various complexity from single body to complex assemblies with a high number of bodies. These bodies are connected to each other with various types of mathematical functions or so called 'joints' (for more details about AVL EXCITE see $[27,28]$ ). The developed friction model should be suitable to be implemented as a friction clutch joint.

For dynamic analyses of vehicle powertrains including a fully functional friction clutch, it is crucial to know the amount of transmitted friction torque through the friction contact at any time and any operation phase of the friction clutch. Therefore the friction model must fulfill these requirements:

1. The friction model must be implemented as a mathematical function or joint, connecting two mechanical parts in the multi-body system (e.g., flywheel and primary gear shaft).

2. AVL EXCITE can provide velocities and displacements of nodes in contact. These data should be the only input for the model.

3. The friction model output must be friction torque.

4. The model should account for all important friction effects.

5. The model must allow for stable numerical process.

6. The model parameters should be as user friendly as possible.

7. The model must be validated by experimental measurements. A good agreement of measured and simulated results must be obtained.

To meet all these requirements, we need to find the most appropriate friction model, adapt it for our needs and validate it against measurements. 


\section{Investigated friction model}

In this research work the Elasto-Plastic (EP) friction model, presented by Dupont et al. $[5,6]$, was investigated as a basis for the friction clutch joint. This model is an advanced upgrade of the original Dahl's friction model [29] and is a member of the so called "Single State Variable" (SSV) friction model family.

Models of the SSV family consider the friction contact as a contact of two brushes, where bristles interact (fig. 1), where, $v_{r}$ is relative sliding velocity and $F$ external tangential load.

$v_{r}>0$

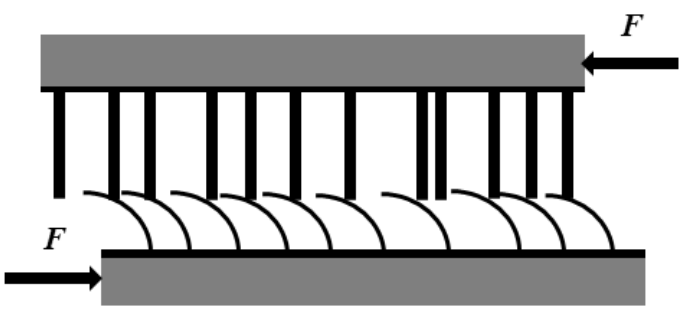

Figure 1: $\quad$ SSV description of the friction contact.

The EP friction model was chosen for further investigations since, according to literature $[5,6]$, it promises to meet all the imposed requirements and is also the only model capable of rendering true stick. The name for the EP friction model comes from solid mechanics, where the terms elastic and plastic are used for reversible and irreversible deformations. Similar the EP model distinguishes between reversible and irreversible displacements of surfaces in contact. The total displacement $x$ consists of the elastic part $z$ called pre-displacement (state variable) and the plastic part $\omega$ (eqn. (2)).

$$
x=z+\omega
$$

The friction force $F_{E P f}$ is defined as follows:

$$
F_{E P f}=\sigma_{0} z+\sigma_{1} \dot{z}
$$

Here, $\sigma_{0}$ denotes the contact stiffness (stiffness of bristles), $\sigma_{1}$ the contact damping and $\dot{z}$ is the velocity of bristle deflection defined by:

$$
\dot{z}=\frac{d z}{d t}=v\left(1-\alpha(z, v) \frac{\operatorname{sign}(v)}{g(v)} z\right)
$$


Tribological characteristics are defined in the function $g(v)$ as follows:

$$
g(v)=\frac{1}{\sigma_{0}} f_{S S}
$$

where, $f_{s s}$ defines the so called Stribeck curve - friction coefficient vs. relative sliding velocity. This function is, according to literature [16-26], most notably responsible for friction dynamics. The definition of the Stribeck curve can be an arbitrary function of sliding velocity for better fitting of measured tribological characteristics. The function $\alpha(z, v)$ controls the friction contact state or phase and is used to achieve stiction.

To meet the requirements discussed in the foregoing text, the function $\alpha(z, v)$ has been modified, since the original definition did not provide useful results for the use at friction clutch simulations. The modification is in detail described in Petrun et al. [30]. Other important properties of the friction model can be found in Dupont et al. [5, 6].

\section{Validation measurements}

To validate the developed friction model against experimental measurements a special test bed was built. A conventional automotive friction clutch is build of many parts. Those are connected to each other in different ways (glue, rivets, bolts, etc.) and the whole friction clutch is a complex multi-body system itself with many unknown parameters. Some of those parameters are hard to estimate, therefore the test bed must be build in such a way, that as many unknown parameters as possible are eliminated from the system. Therefore no conventional, but a special simplified friction clutch was used at the test bed.

The test bed in general consists of two shafts. Each shaft is on one end connected to a torque sensor and an electro motor and on the other end to a disc. One electro motor is used as engine and one as brake. On one discs commercial friction material is mounted. All parts on both shaft assemblies are rigid connected. The friction contact occurs between the outer surfaces of both discs. The actuation on the clutch is hydraulic via a hydraulic axial bearing. The whole test bed assembly can be seen in fig. 2 .

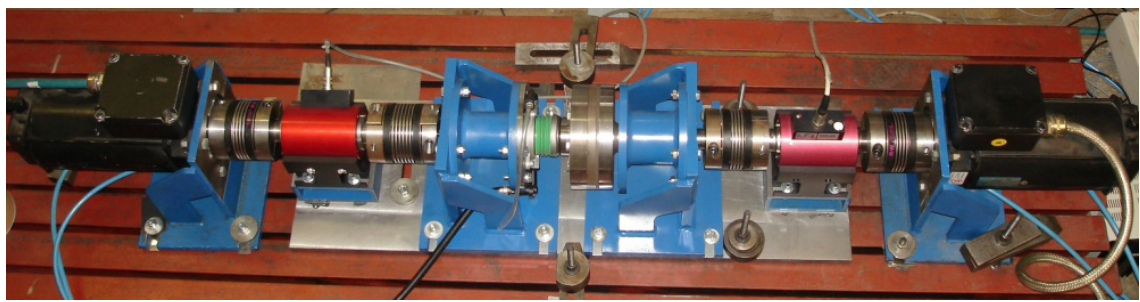

Figure 2: $\quad$ Test bed assembly. 
In this test bed arrangement the only unknowns are the following tribological parameters: friction coefficient, contact stiffness, and contact damping. All other parameters can be obtained either from datasheets or estimated either analytically or with adequate software like AVL EXCITE.

This test bed enables the acquisition of velocities and torques on both sides of the friction contact by employing the LabView interface. The loads and velocities on the engine and on the brake side can be set arbitrarily on the electric motor controller. This makes this test bed suitable to be employed for various load cases and operating regimes in order to test the capabilities and accuracy of the friction model for all friction clutch operation phases.

\section{Simulation model for numerical analysis}

To validate the developed friction model for friction clutch simulations, the whole simulation model must reflect the properties of the test bed assembly to a high accuracy. Therefore a multi-body simulation model was built with the SHAFT MODELER module in AVL EXCITE. The SHAFT MODELER enables easy parametrical modeling of shafts of any geometry. For systems like the test bed used in our work, such models may deliver practically the same results as complex 3D finite element models, but with substantially less modeling and computational effort.

Since all parts of the engine side (ES) and of the brake side (BS) are rigid connected from the electro motor to the disc, we can reduce the number of involved bodies in the model without loss of accuracy (Dolcini et al. [31]). The simulation model is so built of two flexible bodies with exact the same geometry than the corresponding test bed shaft assembly, one for each side of the test bed (fig. 3).

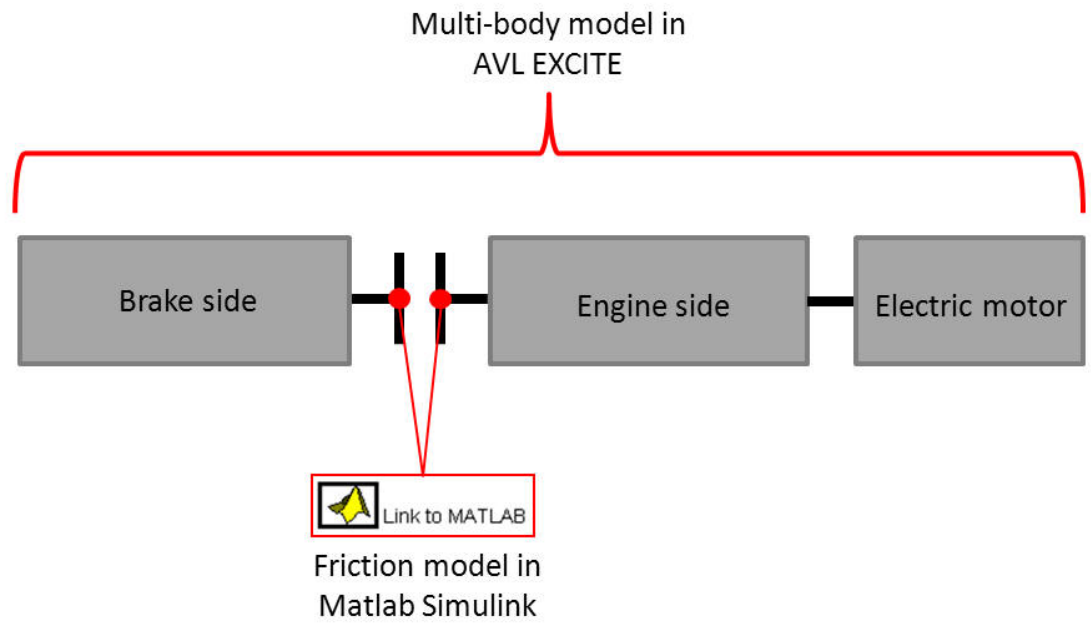

Figure 3: Multi-body simulation model scheme. 
The friction model was coded in MatLab Simulink. Both models were then used together in a co-simulation, where AVL EXCITE calculates the multi-body system dynamics and MatLab Simulink calculates the friction.

The initial and boundary conditions for the simulation were taken directly from the data acquired during the measurements. In order to simplify the comparison of the results, the monitoring points (MP) of the simulation model were defined at the same positions at which the sensors of the test bed are mounted.

\section{Results}

Next, results for some measurement/simulation cases are presented. For each measurement case a parallel numerical simulation was carried out. Also results for a standard chaos model are presented to show the friction dynamic capabilities of the developed friction model.

\subsection{Tribological parameters}

For each experimental case the values of tribological parameters were obtained by experimental measurements. These values were then used for the simulation of the corresponding case. Since the influences of temperature, time, humidity, normal force, velocity, etc. on tribological characteristics and friction dynamics were widely studied by many authors, [16-26], no deeper investigation was made into this.

Here we focused only on the friction coefficient vs. relative sliding velocity curve as the most influencing parameter on friction dynamics [16-26].

\subsection{Stick/slip test}

To test the properties and capabilities of the friction models a stick/slip test was carried out with a "standard" chaos model (fig. 4).

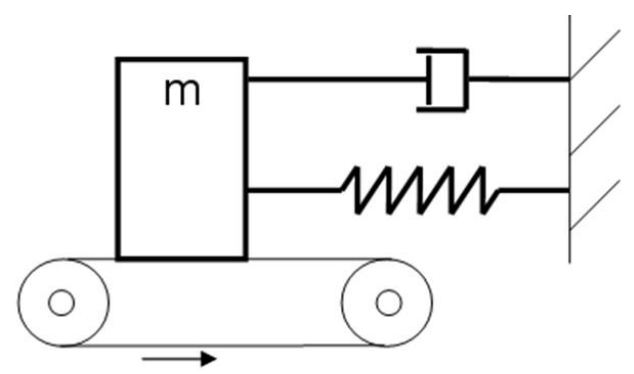

Figure 4: $\quad$ Stick/slip test with chaos model.

As mentioned in the foregoing text, the friction coefficient vs. relative sliding velocity curve has the greatest influence on friction dynamics. This test can be used to prove this statement on different kinds of friction models. Results for two 
models are presented: in fig. 5 the Coulomb friction mode with constant friction coefficient and in fig. 6 the modified EP model with a realistic Stribeck curve. Initial conditions: constant belt velocity of $1 \mathrm{~m} / \mathrm{s}$ and mass velocity of $0 \mathrm{~m} / \mathrm{s}$ were used. The mass of the body was $1 \mathrm{~kg}$, the damping coefficient was $0.1 \mathrm{Ns} / \mathrm{m}$ and the stiffness coefficient was $1 \mathrm{~N} / \mathrm{m}$.

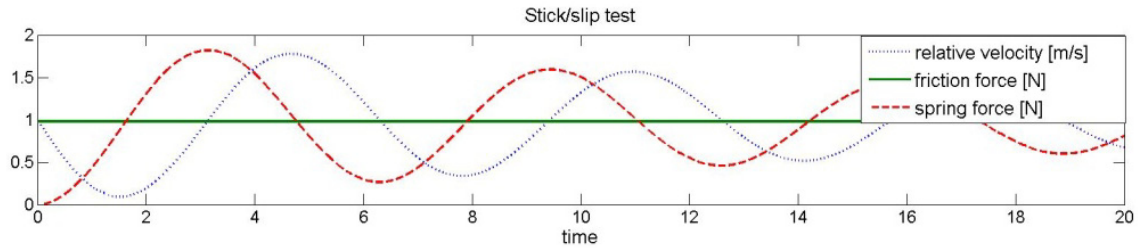

Figure 5: $\quad$ Stick/slip test for Coulomb friction model.

It can be seen, that for the Coulomb friction model the friction force is always constant and the relative velocity and spring force behaviour depend on spring stiffness and damping. Due to constant friction coefficient no stick/slip occurs.

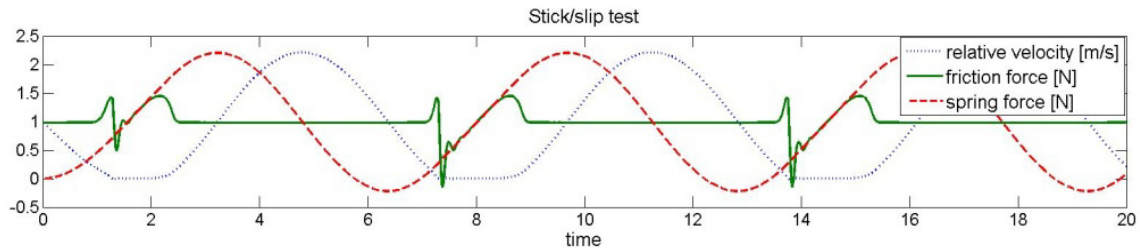

Figure 6: $\quad$ Stick/slip test for modified EP friction model.

In the case of the modified friction model, the friction force is relative velocity dependent in the slip phase and load dependent in the stick phase. We can see an extensive stick/slip occurrence.

\subsection{Validation case: transmitted torque and angular velocities in all operation phases of the friction clutch}

In this section results for one of the validation cases are presented. Here all operation phases of the friction clutch are present. The case considered is quite similar to the actual vehicle powertrain conditions.

As mentioned before, the simulation case was identical to the experimental measurement case. Initial and boundary conditions for the simulation case were taken directly from measurements without smoothing to ensure equal conditions.

The case starts with open friction clutch. At some time normal force is applied as pressure to the hydraulic axial bearing to bring the outer disc surfaces into contact - the synchronization starts. After synchronization finishes, both 
discs rotate with the same rotational velocity-locked phase. The locked phase is maintained for some seconds. During the locked-stick phase the external load is varying in order to demonstrate clearly that the transmitted torque is load dependent. The external load $L$ on BS is acting only if the velocity of the BS is nonzero. After that the normal force is gradually reduced to zero so that breakaway occurs and both shafts return to their initial conditions: ES rotates with $500 \mathrm{rpm}, \mathrm{BS}$ rests at $0 \mathrm{rpm}$.

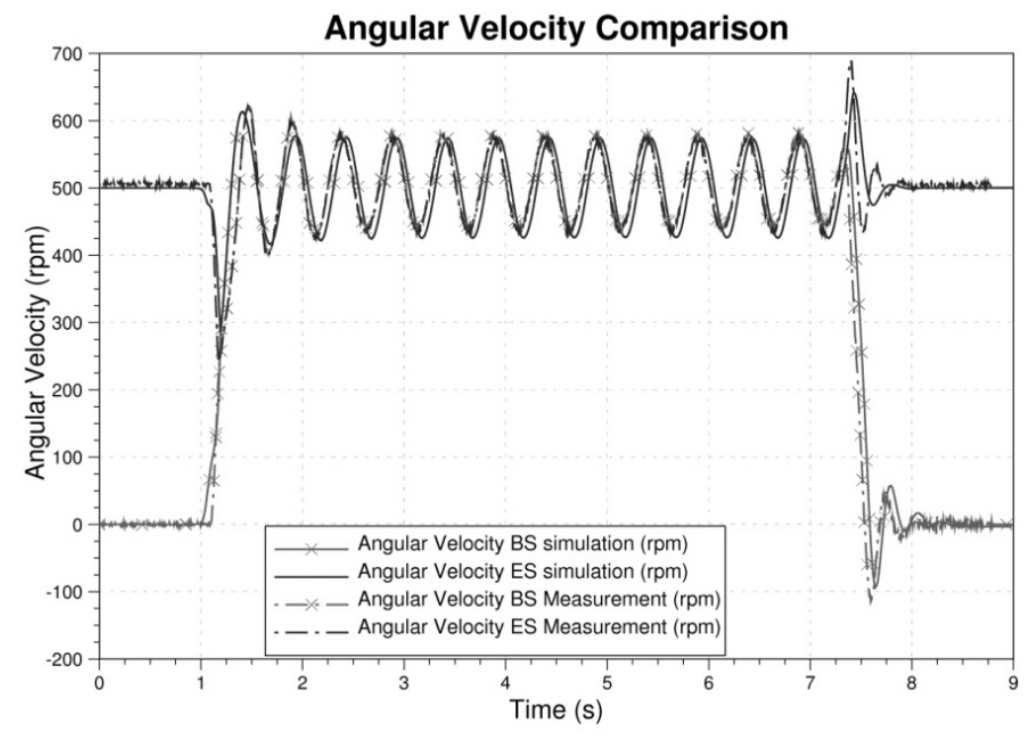

Figure 7: Angular velocity comparison.

In fig. 7 a comparison of angular velocities for the validation case are plotted. We can see a slight difference in the response (delay) of the whole multi-body system. This difference is caused by the electro motor and controller properties in the simulation model, since they are very hard to estimate and they also deviate in reality from properties on the datasheet. In general, very good agreement of measured and simulated values was achieved.

In fig. 8 a comparison of transmitted torques through at the monitoring points (sensor positions) for the validation case are plotted. Similar to section 6.2, we have clearly shown that transmitted torque in the slip phase is a product of normal force, geometry and friction coefficient. On the other hand, in the stick phase the transmitted torque through the friction clutch is external load dependent. Very good agreement of measured and simulated values of transmitted torque was achieved. 


\section{Torque Comparison}

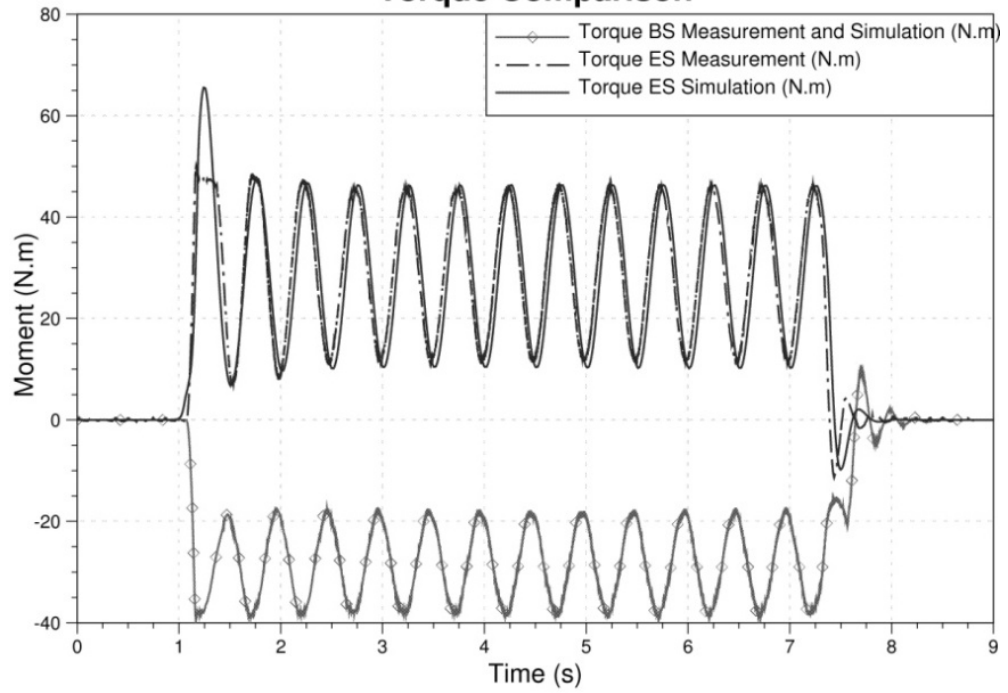

Figure 8: $\quad$ Transmitted torque comparison.

\section{Conclusion}

The presented research work deals with the development and validation of a friction model for numerical simulation of friction clutch dynamics in a powertrain multi-body system. Requirements for the model were imposed by the commercial software code AVL EXCITE, representing the target environment for the model.

As basis for the research, the Elasto-Plastic friction model, presented by Dupont et al. [5, 6], was chosen, since it promises to meet all the imposed requirements, especial the capability to render true stick. The research showed that the original model could not be used directly; therefore a modification was implemented to the original model to settle the inconvenience (Petrun et al. [30]). Nevertheless, all other properties of the original model remain present.

The developed friction model was coded with Matlab Simulink and connected to the multi-body system in AVL EXCITE trough a co-simulation. The modified EP friction model meets all the requirements imposed by its intended use.

For validation purposes a special test bed was built, where realistic operation cases of an automotive friction clutch were measured. Parallel to this, numerical multi-body simulations were carried out. The simulation multi-body system model was identical to the test bed assembly. The results have shown very good agreement between measured experimental results and simulated numerical results. We have also clearly shown that the modified EP friction model is suitable for its intended use since it is able to continuously simulate all operation phases of the friction clutch. 


\section{Acknowledgements}

This research work was partly founded by the European Union, European Social Fund and the Slovenian Technology Agency TIA.

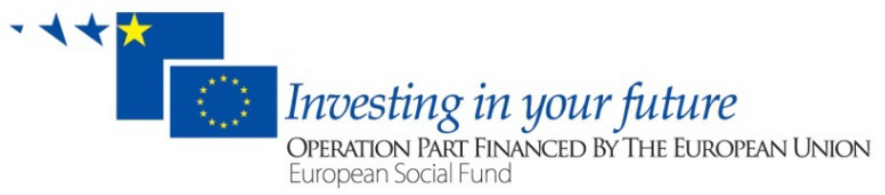

\section{References}

[1] de Coulomb C. A., Théorie des machines simples, en ayant égard au frottement de leurs parties et à la roideur des cordages. French Academy of Science, 1779

[2] Stribeck R., Kugellager für beliebige Belastungen (Ball Bearings for any Stress), Zeitschrift des Vereins Deutscher Ingenieure, 45, 1901.

[3] Stribeck R., Die wesentlichen Eigenschaften der Gleit- und Rollenlager (Characteristics of Plain and Roller Bearings), Zeitschrift des Vereins Deutscher Ingenieure, 46, 1902.

[4] Karnopp D., Computer Simulation of Stick-Slip Friction in Mechanical Dynamic Systems. Journal of Dynamical Systems, Measurement and Control, 107, pp. 100-103, 1985.

[5] Dupont P., Armstrong B., Hayward V., Elasto-Plastic Friction Model: Contact Compliance and Stiction. Proceedings of the American Control Conference, pp. 1072-1077, 2000.

[6] Dupont P., Armstrong B., Hayward V., Altpeter F., Single State Elastoplastic Friction Models. IEEE Transactions on Automatic Control, 47(5), pp. 787-792 2002

[7] Temeltas H., Aktas G., State observation for elastoplastic friction models in positioning systems by utilizing Leunberger observers. Journal of System and Control Engineering, 220(I), pp. 417-426, 2006.

[8] Swevers J., Al-Bender F., Ganseman G. C., Prajogo T., An Integrated Friction Model Structure whit Improved Presliding Behavior for Accurate Friction Compensation. IEEE Transactions on Automatic Control, 45(4), pp. 675-686, 2000.

[9] Freidovich L., Robertsson A., Shiriaev A., Johansson R., LuGre-ModelBased Friction Compensation. IEEE Transactions on Control System Technology, 18(1), pp. 194-200, 2010.

[10] Canudas de Wit C., Olsson H., Astrom K. J., Lischinsky P., A New Model for Control of Systems with Friction. IEEE Transactions on Automatic Control, 40(3), pp. 419-425, 1995. 
[11] Lu Lu, Bin Yao, Qingfeng Wang, Zheng Chen., Adaptive robust control of linear motors with dynamic friction compensation using LuGre model. Automatica, 45, pp. 2890-2896, 2009.

[12] Olsson H., Astrom K. J., Canudas de Wit C., Gafvert M., Lischinsky P., Friction Models and Friction Compensation. European Journal of Control, 4, pp. 176-195, 1997.

[13] Garcia C., Comparison of friction models applied to a control valve. Control Engineering Practice, 16, pp. 1231-1243, 2008.

[14] Rong-Fong Fung, Chang-Fu Han, Jer-Rong Chang., Dynamic modeling of a high-precision self-moving stage with various frictional models. Applied Mathematical Modeling, 32, pp. 1769-1780, 2008.

[15] Armstrong-Helouvty B., Dupont P., Canudas de Wit C., A Survey of Models, Analysis Tools and Compensation Methods for the Control of Machines with Friction. Automatica, 30(7), pp. 1083-1138, 1994.

[16] Vahid-Araghi O., Golnaraghi F., Friction-Induced Vibration in Lead Screw Drives, Springer: New York, 2011.

[17] Nakano K., Two dimensionless parameters controlling the occurrence of stick-slip motion in a 1-DOF system with Coulomb friction. Tribology Letters, 24(2), pp. 91-98, 2006.

[18] Kani H., Miyake J., Ninomiya T., Analysis of the Friction Surface on Clutch Judder, Technical Notes, JSAE Review 13(1), pp. 82-84, 1992.

[19] Karnopp D., Computer Simulation of Stick-Slip Friction in Mechanical Dynamic Systems. Journal of Dynamical Systems, Measurement and Control, 107, pp. 100-103, 1985.

[20] Bostwick C. C., Szadkowski A., Self-Excited vibrations During Engagements of Dry Friction Clutches. SAE Technical Paper Series, SAE No. 982846, 1998.

[21] Centea D., Rahnejat H., Menday M. T., Non-linear multi-body dynamic analysis for the study of clutch torsional vibrations (judder), Applied Mathematical Modeling, 25, pp. 177-192, 2001.

[22] Ost W., De Baets P., Loccufier M., Van Autreve S., Torsional vibrations of wet clutches: influence of mechanical parameters. Mechanica, 45(3), pp 341-353, 2010.

[23] Crowther A., Zhang N., Liu K. D., Jeyakumaran J. K., Analysis and simulation of clutch engagement judder and stick-slip in automotive powertrain systems. Journal of Automobile Engineering, 218(D), pp. 1427-1446, 2004.

[24] Crowther A., Rajendra Singh., Analytical investigation of stick-slip motions in coupled brake-driveline systems. Nonlinear Dynamics, 50, pp. 463-481, 2007.

[25] Ostermeyer G. P., On the dynamics of the friction coefficient. Wear. 254, pp. 852-858, 2003.

[26] Al-Bender F., Swevers J., Characterization of Friction Force Dynamics. IEEE Control System Magazine, 28, pp. 64-81, 2008.

[27] Excite Power Unit Users Guide, Version: AVL EXCITE v2010.1, AVL List GmbH, Graz, 2011. 
88 Tribology and Design II

[28] Excite Power Unit Theory, Version: AVL EXCITE v2010.1, AVL List GmbH, Graz, 2011.

[29] Dahl P.R., A Solid Friction Model. Technical report, TOR-0158(310718)-1. California, The Aerospace Corporation, 1968.

[30] Petrun T., Kegl M., Flašker J., A Reliable Friction Clutch Model for Dynamic Multibody System Simulation, Tribology Letters (in revision process)

[31] Dolcini P. J., Canudas de Wit C., Bechart H., Dry Clutch Control for Automotive Applications, Springer: London, 2010. 